\title{
Theory and Application of Buoyancy in Wells
}

\author{
Eirik Kaarstad (Corresponding author) \\ Department of Petroleum Engineering, University of Stavanger \\ N-4036 Stavanger, Norway \\ Tel: 47-5183-1835Ｅ-mail: eirik.karstad@uis.no \\ Bernt S. Aadnoy \\ Department of Petroleum Engineering, University of Stavanger \\ N-4036 Stavanger, Norway \\ Tel: 47-5183-2256 E-mail: bernt.aadnoy@uis.no
}

Received: January 24, 2011

Accepted: March 6, 2011

doi:10.5539/mas.v5n3p15

\begin{abstract}
The paper presents a generalized buoyancy model for application in wells, called the generalized Archimedes' principle. There exists confusion in the oil industry about buoyancy effects as related to the force-area method (also known as piston force method) or the Archimedes' principle, the stability force in buckling and axial forces during well intervention operations. This paper will present a general model called the generalized Archimedes' principle, which is valid for all cases. Using the generalized Archimedes' principle, a correct assessment of the real axial load of the pipe is obtained, a critical factor for tubular work in petroleum wells. The model is also significant as it is simple and can be applied to all well operations. The paper presents examples of application to ordinary drilling operations, deviated wells and different fluid densities inside and outside the pipe. Two field cases are presented to demonstrate the use of the generalized Archimedes' principle in torque and drag analysis.
\end{abstract}

Keywords: Buoyancy, Effective weight, Deviated wells, Wellhead pressure, Torque and drag analysis

\section{Introduction}

Buoyancy is a very important effect in deep petroleum wells. It is actually a design parameter, where the density of the wellbore fluids is selected to meet several design criteria. The most simple buoyancy calculation is named after the Greek scientist Archimedes of Syracuse. It simply states that buoyancy is equal to the volume of the displaced fluids.

Perhaps the most important publication regarding oil well buoyancy was written by Klinkenberg (1951). At that time several views existed, and Klinkenberg showed that the neutral point can be defined as: "A neutral zone is one in which the stress distribution is isotropic, being the locus of points where the three principal normal stresses are equal". In a discussion in the same paper, Dr. Lubinski and Hawkins supported the view, whereas Woods actually extended the definition to be valid for cases with different fluid densities on the outside and the inside of a pipe. This paper forms the basis for today's understanding of buoyancy, and its implication to pipe failure, pipe buckling and collapse of pipes. The definition of the neutral point in a tubular is fundamental for the buoyancy discussion, and Lubinski (1974) definitions are much used.

In 1980 Goins published two articles (Goins 1980a and 1980b) about this issue. Although not adding fundamental knowledge, Goins managed to show the physics of buoyancy in a simple way, which was an important contribution. In the first article Goins (1980a) showed that "buoyancy is equal to the weight of the displaced fluid" is not always true. Another condition is required, namely that a projected area is required for the fluid pressure to obtain buoyancy. The second article (Goins 1980b) shows calculation procedures and numerical examples that have been widely used because of its clarity.

Patillo and Randall (1980) performed a review of buoyancy models, and identified the confusion in industry with respect to identifying the neutral point of a tubular. They conclude that the force-area method must be used with caution, and they provide considerable insight into buoyancy effects. Aadnoy and Kaarstad (2006) reviewed the fundamental principles as applied to petroleum engineering. Recently Mitchell (2009) presented a fundamental analysis of buoyancy where he included curved boreholes and effects of dynamic flow inside and outside of a 
pipe. He suggested that effects of fluid motion often are negligible.

The above-cited references have had impact on petroleum engineering applications. As it is not the intention to perform a full literature review, we apologize to other authors of buoyancy issues not mentioned.

\section{Fundamental physics of buoyancy}

\subsection{Archimedes' principle}

The Greek scientist Archimedes ( $\sim 300$ B.C.) discovered that the buoyancy of a body equals the weight of the displaced fluid in which it floats. For many applications this definition is sufficient, however, to resolve all problems a more generalized approach must be taken.

The gravitational force acts downwards. Buoyancy is a surface force acting on a body in the opposite direction of the gravitational force. For this reason, it is only pressure acting on the projected vertical area that contributes to buoyancy. The buoyancy force exerted on the body can be calculated by integrating the stress tensor over the surface of the body which is in contact with the fluid:

$F_{b}=\oint_{\mathrm{A}} \sigma \mathrm{dA}$

Integration over a projected surface may become cumbersome for irregular geometries. For an arbitrary body, assume a vertical prism of height, $h$, is cut. The buoyant force equals the difference between the bottom and top force acting on the prism. This force is the hydrostatic pressure times the projected area. Thus, the surface integral is transformed into a volume integral with the help of the Gauss divergence theorem, and the buoyant force becomes:

$\rho_{\text {fluid }} h A=\rho_{\text {fluid }} V$

It can be shown that Eqn. 1 is equal to the weight of the displaced fluid. There are certain conditions for which Eqn. 2 is valid. The fluid must have access to the surface of the body, and the body forces are external forces, which may not reflect the inner forces in the body. Goins (1980a) demonstrated that a projected area is required in order to obtain buoyancy.

The submerged weight of a wellbore tubular is obtained by multiplying the weight in air by a buoyancy factor, $\beta$. See Appendix B for derivations. The following equations are valid both for vertical and deviated boreholes.

$\beta=\frac{\text { Suspended weight in mud }}{\text { Weight in air }}=1-\frac{\rho_{\text {fluid }}}{\rho_{\text {pipe }}}$

The above equation is valid if the inside and the outside of the pipe are submerged in the same fluid. If a different density exists on the inside and the outside, the following equation results (Aadnoy 2006):

$\beta=1-\frac{\rho_{o} r_{o}^{2}-\rho_{i} r_{i}^{2}}{\rho_{\text {pipe }}\left(r_{o}^{2}-r_{i}^{2}\right)}$

For a string composed of many pipe sizes, the effective axial force at any depth and the general expression for the overall buoyancy for a composite string consisting of $\mathrm{n}$ elements is:

$\beta=1-\frac{\sum_{k=1}^{n} D_{k}\left(\rho_{o} r_{o_{k}}^{2}-\rho_{i} r_{i_{k}}^{2}\right)}{\rho_{\text {pipe }} \sum_{k=1}^{n} D_{k}\left(r_{o_{k}}^{2}-r_{i_{k}}^{2}\right)}$

Using Eq. 5 one computes the buoyancy factor starting from the bottom of the string. At any given depth, the axial weight is equal to the pipe weight below multiplied by the buoyancy factor at that depth. An illustrative example is shown in Example 4.6.

Note that both Eq. 4 and Eq. 5 can be applied for a composite string, but that the method is different. Eq. 4 defines the local buoyancy factor for a string element, while Eq. 5 defines the overall buoyancy factor for the string below the point of interest. The difference in application is demonstrated in Examples 4.2 and 4.6.

\subsection{The piston force approach}

In the oil industry there are two "schools" of determining buoyancy. First, the Archimedes' principle, and second 
the piston force or the force-area method. These two approaches give the same pipe weight at surface but may give different loadings throughout the drill string. Considerable confusion exists in the oil industry regarding which criterion is correct.

The piston force is obtained by setting up a force balance. At each size transition a force is obtained equal to the pressure multiplied by the exposed area. This is a one-dimensional approach. If the stability force is subtracted this method yields the same result as the Archimedes' principle (Aadnoy 2006). If this correction is not performed the approach is wrong.

\subsection{What is the correct axial tension?}

There has been considerable debate over the years about the definition of the correct axial tension. Advocates of the force-area method argue that the "real" string tension is given by the summation of forces in the axial direction. Advocates of the Archimedes' principle argue that they calculate the "effective" tension. However, if the "fictitious" force (Lubinski 1974) (also called stability force or buckling force) is subtracted from the force-area, they obtain the same result. This is the correct application of the force-area method.

We will argue that the correct definition of tension depends on the failure criterion chosen because we mainly use axial load in failure assessments. As pure hydrostatic (isotropic) loading of a tubular does not lead to failure it is of no interest. However, failure of metals is governed by distortion as explained in the following.

\section{Mechanistic Approach}

\subsection{Definitions of tubular failure}

An object may be subjected to compressive, tensile, bending and/or torsional load. From the following equation the magnitude of the principal stresses may be determined (Boresi and Schmidt, 2003):

$\sigma^{3}-I_{1} \sigma^{2}-I_{2} \sigma-I_{3}=0$

where $I_{1}, I_{2}$ and $I_{3}$ are the stress invariants.

Further, a total stress state can be decomposed into a hydrostatic and a deviatoric stress component as follows:

$\sigma_{\text {deviatoric }}=\sigma_{\text {total }}-\sigma_{\text {hydrostatic }}$

and a principal stress equation similar to Eqn. 6 above results. However, the invariants are now defined as $J_{1}, J_{2}$ and $J_{3}$. In particular $J_{2}$ is used for failure considerations.

$J_{2}=-\frac{1}{6}\left[\left(\sigma_{1}-\sigma_{2}\right)^{2}+\left(\sigma_{1}-\sigma_{3}\right)^{2}+\left(\sigma_{2}-\sigma_{3}\right)^{2}\right]$

The principle stresses, $\quad 1,2,3$, are defined by the tangential, radial and axial stress components. Some variants of $J_{2}$ are the octahedral shear stress, the von Mises and the Henky-von Mises failure models (Boresi and Schmidt, 2003). In this paper we have not taken into account torsion of the string, but incorporating the shear stress components when calculating the principle stress values in Eq. 8 can include this.

Metals like steel are very strong if loaded hydrostatically, and an eventual failure is due to shear or distortion. Soft rocks, on the other hand may also fail due to hydrostatic loading. Table 1 define likely failure scenario in terms of stress invariants.

We now redefine the issue by defining load in terms of failure mode, instead of searching for the "correct" stress value. For the present case, failure of tubular, we will consider the second deviatoric invariant.

\subsection{Pipe stresses}

The radial and tangential stresses on a thick-walled cylinder can be expressed as:

$\sigma_{r, t}=p_{i}+\left(p_{o}-p_{i}\right)\left\{\frac{1 \mp\left(\frac{r_{i}}{r}\right)^{2}}{1-\left(\frac{r_{i}}{r_{o}}\right)^{2}}\right\}$

One property of these equations is that the sum of the tangential and the radial stresses are constant across the cross-sectional area of the cylinder. 
$\frac{\sigma_{r}+\sigma_{t}}{2}=\frac{p_{o} r_{o}^{2}-p_{i} r_{i}^{2}}{r_{o}^{2}-r_{i}^{2}}$

This result has many implications as follows.

Comparing the general law of Archimedes (Eqn. 4) to the average cross-sectional stress (Eqn. 10), we observe that they are similar.

Eqn. 10 is identical to the "stability forces" or the "fictitious forces" used in buckling analysis.

Using the piston force approach and subtracting Eqn. 10 gives the law of Archimedes.

Eqn. 10 can therefore be defined as the average hydrostatic stress.

In other words, solving for the deviatoric stress, Eqn. 7, by subtracting the average hydrostatic stress, Eqn. 10, we obtain the same axial stress as given by the Archimedes' principle. This stress assessment is valid for all types of failure considerations, shear failure, tensile failure, pipe buckling and collapse of pipe. Equation 4 can be used to compute the submerged weight of any body that is exposed to buoyant forces. There are, however, other effects to consider as well.

\subsection{Applying wellhead pressures}

During live well intervention, a surface pressure is often applied to the annulus or to the drill pipe. Aadnoy (2006) analyzed these cases and found that the generalized law of Archimedes still applies, but end reactions due to surface pressures must be added. Appendix $\mathrm{C}$ shows the derivation of these effects. The results are as follows:

3.3.1 Surface pressure applied to the inside of the tubular

In this case the weight of the string remains unchanged, but an additional axial tension is set up in the string due to the internal pressure $P$. This force is:

$\Delta F=\Delta P A=\Delta P \pi r_{i}^{2}$

3.3.2 Surface pressure applied to the outside of the tubular

If a surface pressure is applied in the annulus only (i.e. tubular closed at bottom), the axial stress remains constant. However, a lift is provided due to a piston effect at the bottom of the pipe. The piston force can simply be computed by calculating the product of $\mathrm{P}$ and the projected area at each change in pipe size (see Fig. 1). The net result at surface is the pressure multiplied by the area at the pipe exit, i.e. the wellhead.

$\Delta F=\Delta P A=\Delta P \pi r_{o}^{2}$

3.3.3 Surface pressure applied to both sides of the tubular

Aadnoy (2006) analyzed the case if a surface pressure is applied both in the annulus and inside the pipe. The result is no change in axial stress, but a lift (hook load reduction) given by Eqn. 12.

Please observe that the solutions above are valid only inside the well. For the pipe outside the well (above the wellhead), there is no external pressure and therefore a different stress state exists.

\subsection{Summary of buoyancy related issues}

To summarize the applications of the models presented:

The general Archimedes' principle is valid for all cases involving tubular submerged in fluids. It gives correct axial load both for tensile strength, buckling and casing collapse analysis. It is valid both for vertical and deviated wells.

The weight of a string in a deviated well is given by the unit weight $(\mathrm{N} / \mathrm{m})$ multiplied by the projected height (Aadnoy et. al., 2003), all multiplied by the buoyancy factor (see Appendix A).

There is always buoyancy in a well (see Appendix B).

For buckling calculations, the generalized law of Archimedes is equivalent to the force-area method corrected for fictitious or stability forces. For a free hanging drill string, the neutral point is at bottom of the pipe.

Applying a surface pressure the following end effects must be added:

Surface pressure inside the pipe have no effect on hook load, but increases tension equal to pressure times pipe internal area.

Surface pressure on the outside or both sides of the tubular is not affecting axial stress, but results in reduced 
hook load equal to pressure multiplied with pipe exit area.

\section{Applications of buoyancy to petroleum wells}

As the generalized Archimedes' principle is valid for all cases, it is simple to use. In the following, different applications are demonstrated using numerical examples. See Tables 2 and 3 for well data.

\subsection{Example calculation: Buoyancy in deviated well}

Table 2 defines the well path for a deviated well and Table 3 describes how the drill string is composed. The well is filled with a $1.5 \mathrm{s.g}$. drilling fluid. The pipe material is steel with a density of $7.8 \mathrm{s.g}$. The buoyancy factor becomes:

$\beta=1-\frac{1.5}{7.8}=0.81$

Applying the projected height principle, the static hook load is:

$W=0.81\left\{0.294\left[\frac{\mathrm{kN}}{\mathrm{m}}\right] 2000[\mathrm{~m}]+2.13\left[\frac{\mathrm{kN}}{\mathrm{m}}\right] 100[\mathrm{~m}]\right\}=0.81 \cdot 801 \mathrm{kN}=649 \mathrm{kN}$

\subsection{Example calculation: Displacing cement}

Assuming the same well as example 4.1, compute the hook load during cement placement. Assume that cement covers the entire depth interval. Compute:

The hook load when 1.8 s.g. cement fills the drill string, and the annulus is filled with 1.5 s.g. mud.

Equation 4 is now used to calculate the buoyancy factor for the respective drill string elements:

Buoyancy of the drill collars:

$\beta=1-\frac{1.5[\text { s.g. }] 8^{2}\left[i n^{2}\right]-1.5[\text { s.g. }] 3^{2}\left[i n^{2}\right]}{7.8[\text { s.g. }]\left(8^{2}\left[i n^{2}\right]-3^{2}\left[i n^{2}\right]\right)}=0.81$

Buoyancy factor for the drill pipe:

$\beta=1-\frac{1.5[\text { s.g. }] 5^{2}\left[i n^{2}\right]-1.5[\text { s.g. }] 4^{2}\left[\mathrm{in}^{2}\right]}{7.8[\text { s.g. }]\left(5^{2}\left[\mathrm{in}^{2}\right]-4^{2}\left[\mathrm{in}^{2}\right]\right)}=0.88$

The hookload now becomes:

$W=0.81 \cdot 2.13\left[\frac{k N}{m}\right] 100[m]+0.88 \cdot 0.294\left[\frac{k N}{m}\right] 2000[m]=690 k N$

Please observe that we have applied the projected height concept (Appendix A) for static weight calculations.

The hook load when the cement fills the annulus, and the string is filled with $1.5 \mathrm{s.g} . \mathrm{mud}$.

Again, using equation 4, the buoyancy factors are calculated. The increased density of the annular fluid results in a decreased buoyancy factor (i.e. increased buoyancy force). Having buoyancy factors of 0.76 for the drill pipe and 0.70 for the drill collars, the following hook load result:

$W=0.70 \cdot 2.13\left[\frac{k N}{m}\right] 100[m]+0.76 \cdot 0.294\left[\frac{k N}{m}\right] 2000[m]=573 k N$

We observe that for case i) with heavy cement inside the pipe, the hook load increases; whereas for case ii) when the cement is displaced to the outside, the hookload is lower.

\subsection{Example calculation: Applying pump pressure inside drill string}

During drilling the pump pressure applied is 300bar $\left(3 \mathrm{kN} / \mathrm{cm}^{2}\right)$. Pressurizing the string has no effect on buoyancy. However, an internal tension is set up inside the drill string. This tension is equal to the pressure multiplied with the internal area of the pipe. The increased tensions become:

In the drill collar: 
$3\left[\frac{k N}{c m^{2}}\right] \pi\left(\frac{3}{2}\right)^{2}\left[i n^{2}\right] 2.54^{2}\left[\frac{c m^{2}}{i n^{2}}\right]=137 k N$

In the drill pipe:

$3\left[\frac{k N}{c m^{2}}\right] \pi\left(\frac{4}{2}\right)^{2}\left[i n^{2}\right] 2.54^{2}\left[\frac{c m^{2}}{i n^{2}}\right]=243 k N$

\subsection{Example calculation: Shut-in and pressurized annulus}

Assume that the wellhead is shut in and a pressure of $50 \mathrm{bar}\left(0.5 \mathrm{kN} / \mathrm{cm}^{2}\right)$ is applied in the annulus. Assume static pipe, that is, no friction at the shut-in point. As discussed earlier, the same effect results if the pipe is open or closed. The effective axial stress remains constant, but an end reaction is set up resulting in a reduced hook load. This reduction is equal to the shut-in pressure multiplied with the exit area at the wellhead, that is:

$0.5\left[\frac{k N}{c m^{2}}\right] \pi\left(\frac{5}{2}\right)^{2}\left[i n^{2}\right] 2.54^{2}\left[\frac{\mathrm{cm}^{2}}{\mathrm{in}^{2}}\right]=63 k N$

The hook load is now $649 \mathrm{kN}-63 \mathrm{kN}=586 \mathrm{kN}$.

\subsection{Example calculation: Well intervention operations}

The traditional way to compute forces during well intervention operations is to use the piston-force approach, which implies computing total forces and subtracting the stability forces. We will propose an alternative method by simply using the buoyancy factor and to add end reactions. Example 4.4 illustrates the application of this simple principle. The results are of course identical.

One can easily determine the "pipe light" condition where the pressure is pushing the pipe out of the well by the following force balance:

$\mathrm{F}_{\text {push }}=\Delta P A=\beta w D_{T V D}$

\subsection{Example calculation: Buoyancy in a tapered string}

The composite equation Eq. 5 is very useful to determine the axial load throughout a tubular from bottom to top. As real drilling or production strings often consists of various tubular sizes, it can be useful to know the exact axial load of each component.

Below a simple example is given to demonstrate the application of Eq. 5. Table 4 defines a tapered string, landed in a $1.4 \mathrm{s.g}$. drilling mud. The inside of the drilling string is filled with $1.8 \mathrm{s.g}$. mud.

Applying Eq. 5 the overall buoyancy factor can be calculated throughout the string. Table 5 gives the result. See Appendix D for details on how the overall buoyancy factors are calculated.

Assuming the bit off bottom, the axial force on top of the drill collars is:

$F_{d c}^{t o p}=0.83 \cdot 2.13\left[\frac{\mathrm{kN}}{\mathrm{m}}\right] 100[\mathrm{~m}]=177 \mathrm{kN}$

The axial force at top of the HWDP becomes:

$F_{H W D P}^{t o p}=0.84 \cdot\left(2.13\left[\frac{k N}{m}\right] 100[m]+0.62\left[\frac{k N}{m}\right] 300[m]\right)=335 k N$

The axial load at top of 5 in DP becomes:

$F_{D P}^{t o p}=0.86 \cdot\left(2.13\left[\frac{k N}{m}\right] 100[m]+0.62\left[\frac{k N}{m}\right] 300[m]+0.294\left[\frac{k N}{m}\right] 500[m]\right)=470 k N$

And the hook load becomes:

$$
\begin{aligned}
F^{\text {Hookload }}=0.88 & \cdot\left(2.13\left[\frac{\mathrm{kN}}{\mathrm{m}}\right] 100[\mathrm{~m}]+0.62\left[\frac{\mathrm{kN}}{\mathrm{m}}\right] 300[\mathrm{~m}]+0.294\left[\frac{\mathrm{kN}}{\mathrm{m}}\right] 500[\mathrm{~m}]\right. \\
& \left.+0.73\left[\frac{\mathrm{kN}}{\mathrm{m}}\right] 1000[\mathrm{~m}]\right)=1122 \mathrm{kN}
\end{aligned}
$$


Figure 2 show both the cumulative buoyancy factor and the axial load throughout the drill string.

\section{Field cases}

To verify the effectiveness of the model we present two field cases where the buoyancy effect is prominent. When running in hole (RIH) with a drill string, a float valve is often used. The float valves provide added blowout protection at the bottom of the drill string, prevent flow-back when making connections and keeps cuttings out of the drill string. It is important to fill the drill pipe regularly (e.g. every 1000 mMD) when RIH. Failure to do so will increase the collapse load on the drill string and can cause damage to the drill pipe and/or the float valve. In a depth plot there is a step change in the hook load every time the pipe is being filled (see Figures 4 and 6).

In the following field cases two North Sea wells with different well profiles are studied. For calculating the hook load while RIH, an analytical 3-dimensional torque and drag model (Aadnoy et. al. 2009) was applied.

\subsection{Field case \#1}

The first well is a $5300 \mathrm{mMD}$ long horizontal well. It kicks off from $350 \mathrm{mMD}$ and builds to 30 degrees at 1200 $\mathrm{mMD}$. Then there is a sail section down to $2750 \mathrm{mMD}$. The second build section ends horizontally at about 4500 mMD. A more detailed study of the drag forces in this well can be found in Mirhaj et. al. (2010a).

During RIH of this well the pipe is filled with mud every $1000 \mathrm{mMD}$. The drill string must now be projected onto the vertical depth axis before equation (5) can be used to calculate the buoyancy factor through the drill string (see Example 4.6 for example calculation). This exercise is repeated as the drill string is RIH. The result is shown in figure 3 where the overall buoyancy factor is plotted as a function of the bit depth.

However, for a given bit depth the local cumulative buoyancy factor through the drill string will vary as function of depth as shown in figure 2. The result is that when we calculate the axial load on the drill string, the local buoyancy factor applied on a drill string element is found from the cumulative buoyancy factor curve at the depth of interest. The local buoyancy factor at a given depth will therefore vary depending on the bit depth. Hence, the buoyancy factor is a dynamic parameter that is changing as the drill string is RIH. When calculating the local buoyancy factor on a drill string that is lifted or lowered, we may say that a dynamic buoyancy factor (DBF) model is applied.

Figure 3 clearly shows that there is a large variation in the overall buoyancy factor depending on the amount of air in the drill string. Obviously, this variation in buoyancy factor will be reflected in the hook load as the drill string is being RIH. Figure 4 shows the recorded hook load data together with the modelled lowering force while RIH. For comparison, also the modelled data using one single buoyancy factor is included.

The modelled data using the DBF model clearly give a better match than the single buoyancy factor model. Using the DBF enables us to accurately predict the naturally step-shaped hook load while RIH so that other factors affecting the hookload may be recognized at an early stage.

\subsection{Field case \#2}

Well number 2 is a shallow horizontal well with large turns in both upper and lower part of the well. The well kicks off from about $400 \mathrm{mMD}$ and builds up to horizontal at $2300 \mathrm{mMD}$ at $1600 \mathrm{mTVD}$. The last run in the well went from $3000 \mathrm{mMD}$ to $5000 \mathrm{mMD}$. Also for this well a more detailed study of the drag forces is performed by Mirhaj et. al. (2010b).

As for the previous field case, there is a large variation in the overall buoyancy factor with increasing bit depth. However, there is one distinct difference. Because of the shallow vertical depth of this well, the effect of buoyancy in this well is higher at large bit depths. This can be seen in figure 5 where the overall buoyancy factor is plotted against the bit depth.

The DBF model can now be applied to calculate the lowering force of the drill string while RIH. Figure 6 shows how the modelled data fits the recorded hookload data when applying the DBF model. The simplicity of applying the DBF model into the 3-dimensional torque and drag model clearly proves it to be a powerful tool for accurate torque and drag calculations.

\subsection{Summary of field cases}

Field cases 1 and 2 have demonstrated the need for correct buoyancy factors in drag calculations when there are different fluids densities present in the hydraulic system. In these field cases the fluids were mud and air, but the equation is general and any combination of fluids can be applied depending on the operation being analyzed. 


\section{Summary and conclusions}

The paper presents a generalized buoyancy model for application in wells called the generalized law of Archimedes, which is valid for both vertical and deviated wells, tubular with different fluid densities in-/outside, and if surface pressures are applied.

Different numerical examples of the different application scenarios are given in the paper. Also, two North Sea field cases demonstrate the need for correct assessment of the dynamic buoyancy factor when modelling the lowering force of the drill string during running in hole.

Using the generalized law of Archimedes, a correct assessment of the real axial load of the pipe is obtained, a critical factor for tubular work in petroleum wells. The model is also significant as it is simple and can be applied to all well operations.

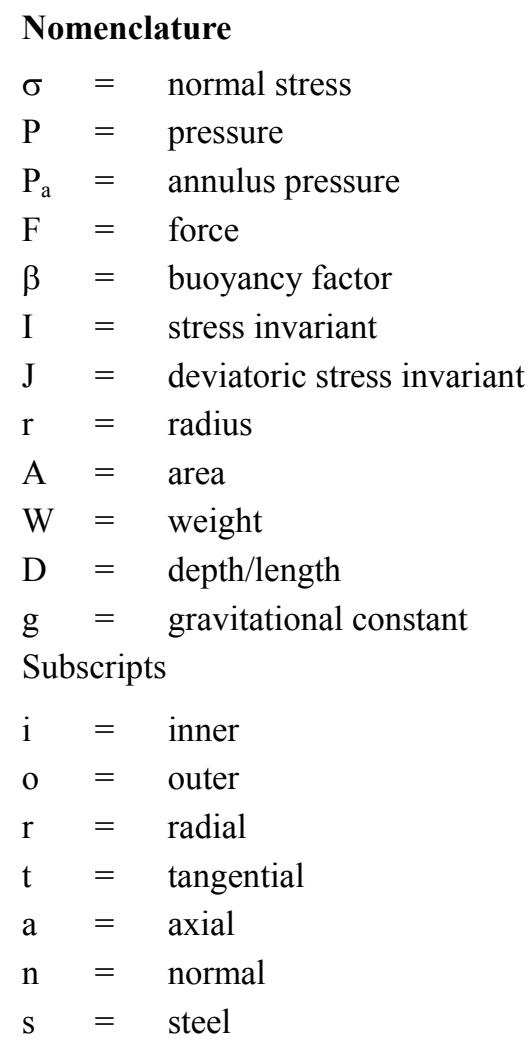

\section{References}

Aadnoy, B.S. (2006). Mechanics of Drilling, Shaker Verlag, Aachen, 2006, ISBN 3-8322-4861-7.

Aadnoy, B.S. and Kaarstad, E. (2006). Theory and Application of Buoyancy in Wells. Paper IADC/SPE 101795 presented at the 2006 IADC/SPE Asia pacific Drilling Technology Conference and Exhibition, Bangkok, Thailand, 13-15 November 2006.

Aadnoy, B.S., Larsen, K. and Berg, P.C. (2003). Analysis of Stuck Pipe in Deviated Boreholes, The Journal of Petroleum Science and Engineering, 37(2003) 195-212.

Boresi, A.P., Schmidt, R.J. (2003). Advanced Mechanics of Materials, 6th ed., Wiley, ISBN 0-471-43881-2

Goins, W. C. (1980). Better understanding prevents tubular buckling problems. Part 1- Buckling tendency, causes and resulting problems are described, World Oil, January 1980, pp. 101-105.

Goins, W. C. (1980). Better understanding prevents tubular buckling problems. Part 2- Graphic solutions are presented for field situations, World Oil, February 1980, pp. 35 - 40.

Klinkenberg, A. (1951). The neutral zones in drill pipe and casing and their significance in relation to buckling and collapse, Drilling and Production practice, American petroleum Institute, 1951, pp. 64 - 76.

Lubinski, A. (1974). Influence of neutral axial stress on yield and collapse of pipe, Paper presented at the Petroleum Mechanical Engineering Conference, Dallas, Texas, 15-18 September.

Mirhaj, A.M., Kaarstad, E., and Aadnoy, B.S. (2010a). New Aspects of Torque-and-Drag Modeling in 
Extended-Reach Wells. Paper SPE 135719 presented at the SPE Annual Technical Conference and Exhibition, Florence, Italy, 19-22 September 2010.

Mirhaj, A.M., Kaarstad, E., and Aadnoy, B.S. (2010b). Minimizing Friction in Shallow Horizontal Wells. Paper SPE/IADC 135812 presented at the IADC/SPE Asia Pacific Drilling Technology Conference and Exhibition, Ho Chi Minh City, Vietnam, 1-3 November 2010.

Mitchell, R.F. (2009). Fluid Momentum Balance Defines the Effective Force. Paper SPE/IADC 119954 presented at the 2009 SPE/IADC Drilling Conference and Exhibition, Amsterdam, the Netherlands, 17-19 march 2009.

Patillo, P. D. and Randall, B. V. (1980). Two Unresolved Problems in Wellbore Hydrostatics. Part 1 Determination of the Neutral Point in a Drill String, Petroleum Engineer International, July 1980, pp. 24 - 32.

Table 1. Likely failure conditions in terms of invariants

\begin{tabular}{llcc}
\hline Material: & Failure type & Deviatoric failure (distortion): & Hydrostatic failure: \\
\hline Metals & Shear & $\mathrm{J}_{2}$ & \\
& Tension & $\mathrm{J}_{2}$ & \\
& Buckling & $\mathrm{J}_{2}$ & \\
& Collapse & $\mathrm{J}_{2}$ & \\
Rocks & & $\mathrm{J}_{2}$ & $\mathrm{I}_{1}$ \\
Soft materials & & $\mathrm{J}_{2}, \mathrm{~J}_{3}$ & $\mathrm{I}_{1}$ \\
\hline
\end{tabular}

Table 2. Well path data for deviated well

\begin{tabular}{lcccc}
\hline Position: & Depth $m$ TVD & Depth $m$ MD & Inclination $\left(^{\circ}\right)$ & Radius $(m)$ \\
\hline Kick-off depth & 1000 & 1000 & 0 & - \\
End build-up & 1433 & 1524 & $0-60$ & 500 \\
Top drill collars & 2000 & 2658 & 60 & - \\
Drill bit & 2100 & 2858 & 60 & - \\
\hline
\end{tabular}

Table 3. Drill string data

\begin{tabular}{lccc}
\hline Tubular: & Unit weight $(\mathrm{kN} / \mathrm{m})$ & Total length $(\mathrm{m})$ & Total weight $(\mathrm{kN})$ \\
\hline $5 \times 4$ in drill string & 0.294 & 2658 & 781 \\
$8 \times 3$ in. drill collars & 2.13 & 200 & 426 \\
Total weight $(\mathrm{kN})$ & & & 1207 \\
\hline
\end{tabular}

Table 4. Data for tapered drill string

\begin{tabular}{lccc}
\hline Pipe: & Depth $m$ TVD & Size & Weight $(k N / m)$ \\
\hline Drill pipe -1 & 1000 & $6 \% / 8 \times 5$ & 0.73 \\
Drill pipe -2 & 1500 & $5 \times 4$ & 0.294 \\
HWDP & 1800 & $5 \times 3$ & 0.62 \\
Drill collars & 1900 & $8 \times 3$ & 2.13 \\
\hline
\end{tabular}


Table 5. Overall buoyancy factors for tapered string

\begin{tabular}{lcc}
\hline Pipe: & Depth $m$ TVD & Buoyancy factor, $\beta$ \\
\hline Drill pipe -1 & $0-1000$ & 0.88 \\
Drill pipe -2 & $1000-1500$ & 0.86 \\
HWDP & $1500-1800$ & 0.84 \\
Drill collars & $1800-1900$ & 0.83 \\
\hline
\end{tabular}

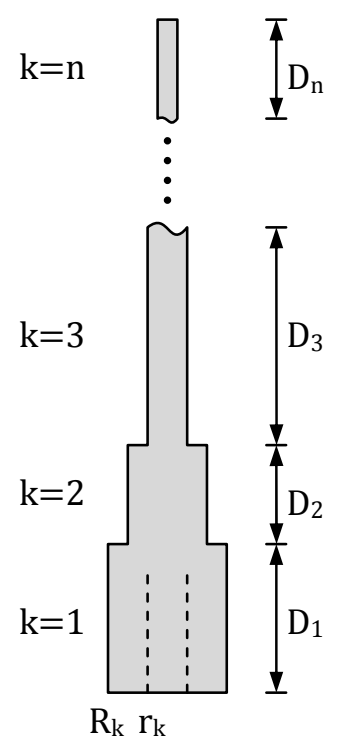

Figure 1. Composite string with different densities inside and outside

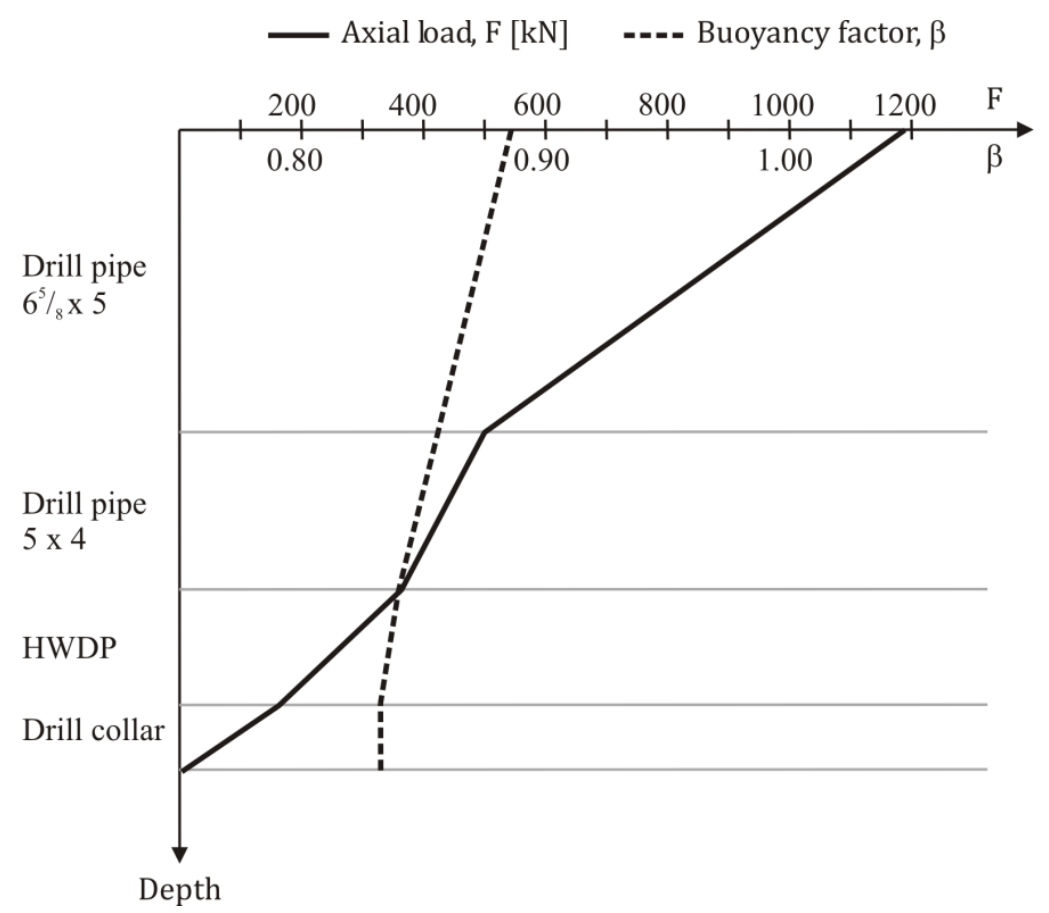

Figure 2. Cumulative buoyancy factor and axial load for Example 4.6 


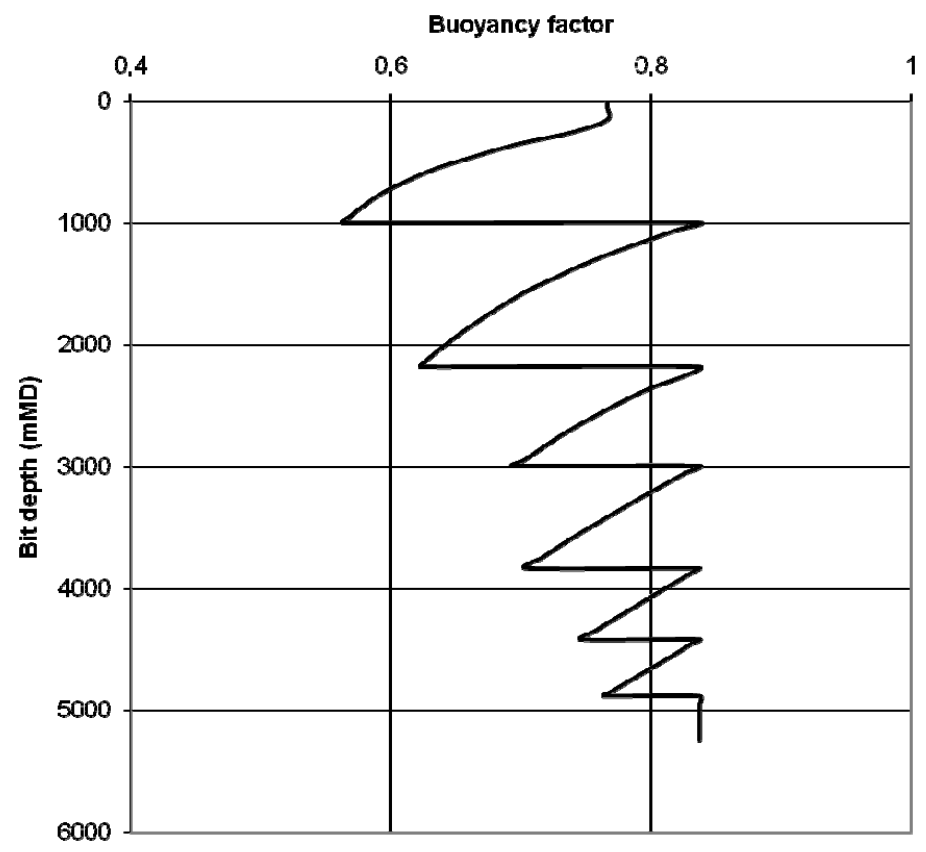

Figure 3. Overall buoyancy factor vs. bit depth for well \#1

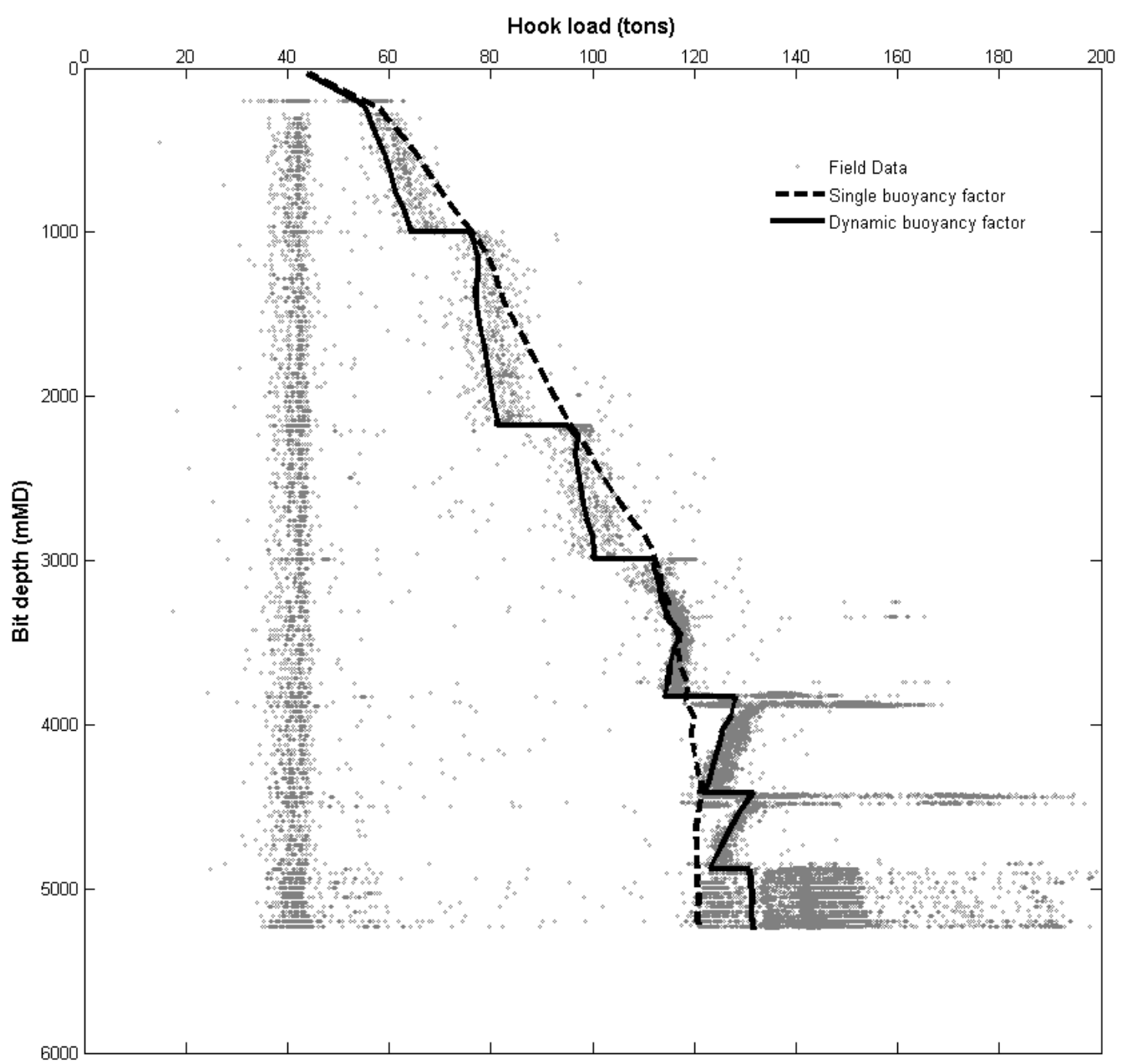

Figure 4. Comparison between field data and modelled lowering force during RIH for well \#1 


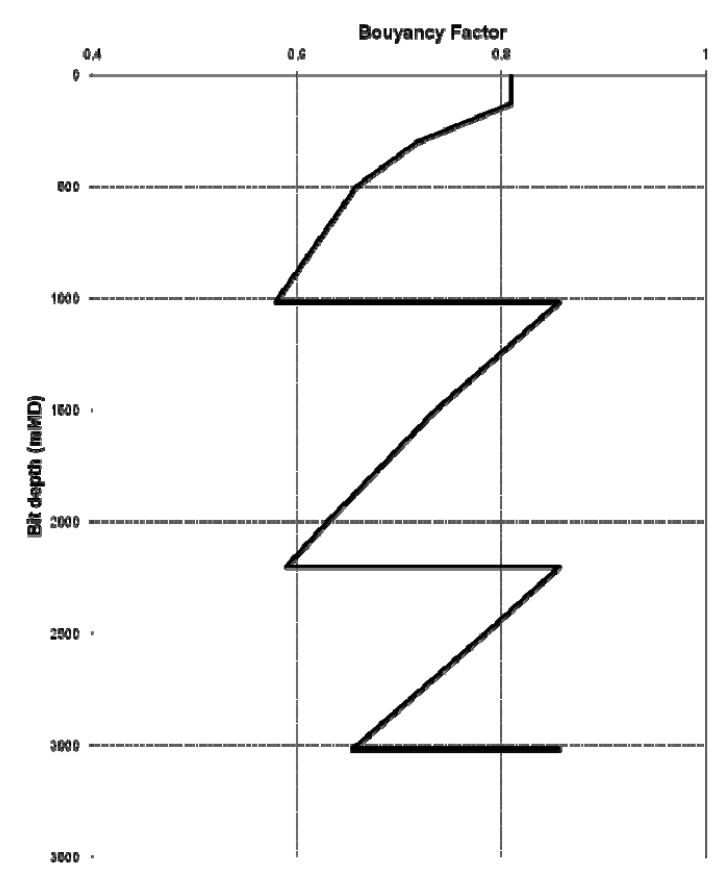

Figure 5. Overall buoyancy factor vs. bit depth for well \#2

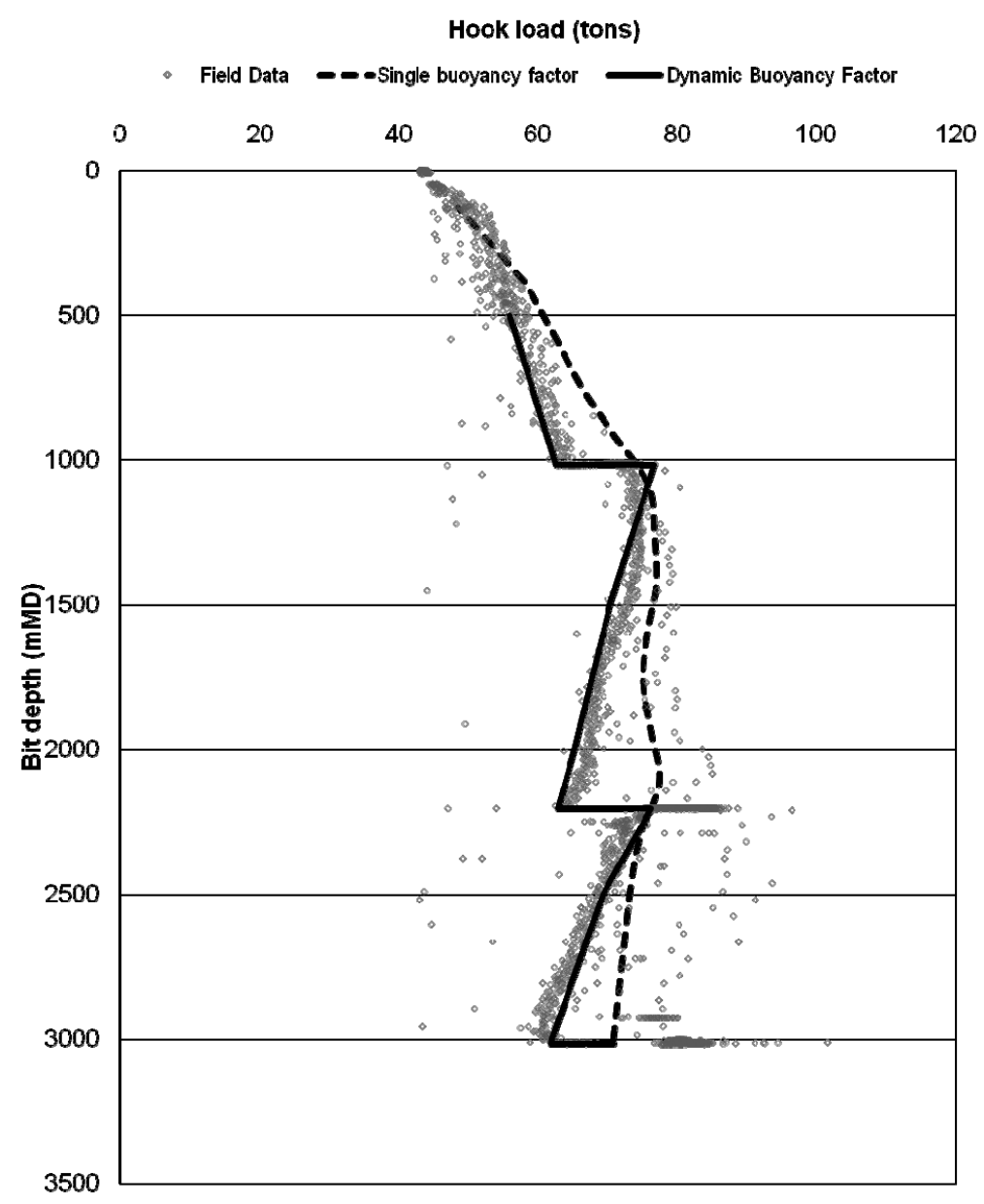

Figure 6. Comparison between field data and modelled lowering force during RIH for well \#2 


\section{Appendix A - The projected height concept}

Figure A-1 shows a tubular resting on the low side in a deviated borehole. The weight of the pipe can be decomposed into an axial component and a normal component as follows:

$W[N]=w\left[\frac{N}{m}\right] L[m]$

$W_{a}=W \cos \alpha=w L \cos \alpha$

$W_{n}=W \sin \alpha=w L \sin \alpha$

From inspection of the geometry of the inclined pipe, the following relationship exists between the pipe length $\mathrm{L}$ and the vertical projection:

$D_{T V D}=L \cos \alpha$

Combining eqns. A.1 and A.2, the axial weight component can be expressed as:

$W_{a}[N]=w\left[\frac{N}{m}\right] D_{T V D}[m]$

This is an important result. As the weight of the pipe at surface equals the unit weight multiplied with the entire length, the weight in the well is given by the unit weight multiplied with the projected height. Using this concept it is easy to assess the hook load by the pipe weight and the projected height. This is valid for any well path.

The above equation neglects friction. For a pipe in motion combining eqns. A.1 and A.2 we obtain the normal force:

$W_{n}[N]=w\left[\frac{N}{m}\right] D_{T V D}[m] \tan \alpha$

Eqn. A.4 is useful when well friction is considered. Please observe that the above derivations do not take buoyancy into account. In the following the buoyancy factor will be derived. The axial weight in the well is then Eqn. A.3 multiplied with the buoyancy factor.

\section{Appendix B - The buoyancy factor}

\section{B.1 Vertical pipe}

First consider a pipe hanging off bottom in a vertical well as shown in Fig. B-1. The weight of the tubular is:

$W[N]=w\left[\frac{N}{m}\right] D[m]=\rho_{\text {pipe }} g A\left[m^{2}\right] D[m]$

The unit weight is expressed as a product of the density of the tubular material multiplied with the cross-sectional area and the length.

When submerged in a fluid, a hydrostatic force acts on the bottom surface providing a lift. This force is equal to the bottom-hole pressure multiplied with the cross-sectional area of the pipe, or:

$F_{\text {hydrostatic }}=\rho_{\text {fluid }} g D A$

The net pipe weight is the difference between the surface pipe weight and the buoyant force or:

$W_{\text {buoyed }}=\left(\rho_{\text {pipe }}-\rho_{\text {fluid }}\right) g D A$

Now defining the buoyant force as a buoyancy factor, $\beta$, multiplied with the surface pipe weight:

$W_{\text {buoyed }}=\left(\rho_{\text {pipe }}-\rho_{\text {fluid }}\right) g D A=\beta \rho_{\text {pipe }} g D A$

The buoyancy factor can then be expressed as:

$\beta=1-\frac{\rho_{\text {fluid }}}{\rho_{\text {pipe }}}$

\section{B.2 Deviated pipe}

Figure B-2 shows the pipe submerged into a deviated well. Observe that both the weight (gravity) and the piston force on the pipe element act in a vertical direction. The piston force is now acting on the projected pipe area. Eqn. A.1 defines the axial and normal components of the pipe weight.

The weight and the buoyant force always act in opposite directions on a pipe, regardless of pipe orientation. Also, 
they act of the very same areas (Archimedes defines buoyancy as the weight of the displaced fluid.) Therefore, the buoyancy factor is equally valid for deviated wells as for vertical wells. One difference is that for the vertical well, the buoyancy acts at the bottom end of the pipe, whereas for a deviated well the buoyant force is distributed throughout the length of the pipe.

B.3 Effect of end condition for deviated pipe

If an open-ended pipe is rammed into the bottom of a perfectly straight vertical well, it is theoretically possible that buoyancy is lost, and that the hook loads seen is the surface weight of the string. For this case, the bottom pressure has no longer access to the bottom of the pipe, and there is no projected area of the pipe to provide buoyancy.

A real well is never perfectly vertical, and therefore some projected area will be exposed to provide buoyancy. With reference to Figure B-2, full buoyancy is obtained if the pipe deviates from vertical providing one cross-sectional area projected.

Real wells deviate from perfect vertical wells by doglegs or deviation. It is therefore our opinion that buoyancy will always be present, whether the pipe end is exposed to pressure or not. Figure B-3 illustrates the end effect for a deviated pipe.

B.4 Comparison vertical and deviated well

The example below shows how the buoyant force acts throughout the tubular for different inclinations. For the vertical pipe it acts at the bottom end surface only. For the deviated pipe the buoyancy is distributed along the pipe length, resulting in a different force profile. Actually for the deviated pipe, the correct axial force is obtained by multiplying with the buoyancy factor, as illustrated in Figure B-4. To illustrate the buoyant forces, we have drawn projected planes throughout the pipe of Figure B-4. At each plane a buoyant force arise as indicated in the lower figure. The discrete steps are for illustration only. The continuous line given by the Archimedes' principle describes the real axial tension.

Figure B-4 shows that the buoyant forces are always distributed throughout the string. The reason is the projected surface is found from bottom to top. The case of a perfect straight pipe exposing only the end surface is not expected to occur in a real well and is therefore neglected.

Based on this we can conclude that there is always buoyancy present in a liquid filled well.

\section{Appendix C - Effects of shut-in wellhead pressure}

The generalized law of Archimedes defines the axial loading for all cases involving buoyancy effects. If a surface pressure is applied inside the string or in the annulus it should be evaluated as an end reaction to be added to the buoyed weight of the pipe. A schematic view of surface applied pressures is shown in Figure C-1. The resulting pressures in the drill pipe and annulus are shown in Table C-1.

Now assume a drill string as shown in Figure C-2, subjected to the loadings described in Table C-1. For each case the uniaxial forces (piston force), average hydrostatical force and the deviatoric force is calculated for the different components of the drill string. The calculated values of the respective forces are shown in Tables C.1 C.3. Aadnoy (2006) shows the effect of end reactions on the uniaxial forces and deviatoric forces in the following way.

\section{C.1 Surface pressure applied inside the string}

Comparing the expressions in Table C-2 with the results of Appendix B, it is clear that the buoyed weight of the drill string remains constant when a surface pressure is applied inside the drill string. The weight is still given by the principle of Archimedes. The three-dimensional stress state is changed, however, due to the internal surface pressure, and must be taken into account in failure calculations of the drill pipe. The axial tension increase due to the inside surface pressure is equal to $\Delta P \pi r_{i, n}{ }^{2}$, where $n$ is the pipe element under consideration. For uniaxial failure considerations, this force should be added.

\section{C.2 Surface pressure applied in the annulus}

The net result shown in Table C-3 is that the deviatoric loading is the same whether or not a surface pressure is applied. However, an end reaction is set up providing a lifting force. Hook load reduction is equal to the surface pressure times the exit area of the pipe (see Figure C-2b).

C.3 Surface pressure on both sides of the string

For this case, the additional surface pressure will again cause a lifting force in the string as in the previous case. Comparing the expressions in Table C-4 with the results of Eq. A.2, it is clear that the deviatoric force remains constant when a surface pressure is applied inside and outside the drill string. The deviatoric force is given by the principle of Archimedes. The hookload, as seen on surface, decreases.

\section{Appendix D - Determination of overall buoyancy factor (ref. Example calculation 4.6)}

In Example 4.6 the axial load is calculated throughout a tapered string from bottom to top. For determination of the axial load at a given depth, the overall buoyancy factor is applied at that given depth. As an arithmetic 
exercise and to demonstrate the application, this appendix gives the mathematical details on how to calculate the overall buoyancy factors.

Because the overall buoyancy factor at a given depth depends on all the elements below that depth one has to calculate from bottom to top. Given a tapered drill string as described in Table 4, 4 different buoyancy factors have to be determined (see Tables D-1 and D-2).

Applying Eq. 5, the following buoyancy factors result (note that diameters are used instead of radii as this will give the same result) as shown in Table D-2. The results of Table D-2 are shown in Figure 2.

\section{Appendix tables}

Table C-1 - Pressures in drill pipe and annulus during shut-in

\begin{tabular}{|l|l|l|}
\hline Shut-in pressure & Pressure in annulus, $P_{a}$ & Pressure in drill pipe, $P_{d p}$ \\
\hline Case C.1: Drill pipe only & $P_{a}=\rho g D$ & $P_{d p}=\rho g D+\Delta P$ \\
\hline Case C.2: Annulus only & $P_{a}=\rho g D+\Delta P$ & $P_{d p}=\rho g D$ \\
\hline Case C.3: Both drill pipe and annulus & $P_{a}=\rho g D+\Delta P$ & $P_{d p}=\rho g D+\Delta P$ \\
\hline
\end{tabular}

Table C-2 - Forces in drill string with external loading in drill pipe

\begin{tabular}{|l|c|c|c|}
\hline & Piston force & Average hydrostatic force & Deviatoric force \\
\hline Btm of DC & $-\rho g D \pi r_{o_{2}}^{2}+(\rho g D+\Delta P) \pi r_{i_{2}}^{2}$ & $-\rho g D \pi r_{o_{2}}^{2}+(\rho g D+\Delta P) \pi r_{i_{2}}^{2}$ & 0 \\
\hline Top of DC & $\Delta \rho g D_{2} \pi \Delta r_{2}^{2}-\rho g D_{1} \pi \Delta r_{2}^{2}+\Delta P \pi r_{i_{2}}^{2}$ & $-\rho g D_{1} \pi r_{o_{2}}^{2}+\left(\rho g D_{1}+\Delta P\right) \pi r_{i_{2}}^{2}$ & $\Delta \rho \Delta r_{2}^{2} g \pi D_{2}$ \\
\hline Btm of DP & $\Delta \rho g D_{2} \pi \Delta r_{2}^{2}-\rho g D_{1} \pi \Delta r_{1}^{2}+\Delta P \pi r_{i_{1}}^{2}$ & $-\rho g D_{1} \pi r_{o_{2}}^{2}+\left(\rho g D_{1}+\Delta P\right) \pi r_{i_{2}}^{2}$ & $\Delta \rho \Delta r_{2}^{2} g \pi D_{2}$ \\
\hline Top of DP & $\Delta \rho g \pi\left[D_{1} \Delta r_{1}^{2}-D_{2} \Delta r_{2}^{2}\right]+\Delta P \pi r_{i_{1}}^{2}$ & $\Delta P \pi r_{i_{2}}^{2}$ & $\Delta \rho g \pi\left[D_{1} \Delta r_{1}^{2}+D_{2} \Delta r_{2}^{2}\right]$ \\
\hline Hook load & \multicolumn{3}{|c|}{$\Delta \rho g \pi\left[D_{1} \Delta r_{1}^{2}+D_{2} \Delta r_{2}^{2}\right]=$ Static weight } \\
\hline
\end{tabular}

where $\Delta \rho=\left(\rho_{\text {pipe }}-\rho_{\text {fluid }}\right)$ and $\Delta r_{k}^{2}=\left(r_{o_{k}}^{2}-r_{i_{k}}^{2}\right)$, where $k=1 \rightarrow$ drill pipe, and $k=2 \rightarrow$ drill collar.

Table C-3 - Forces in drill string with external loading in annulus

\begin{tabular}{|l|c|c|c|}
\hline & Piston force & Avg. hydrostatic force & Deviatoric force \\
\hline Btm of DC & $-(\rho g D+\Delta P) \pi r_{o_{2}}^{2}+\rho g D \pi r_{i_{2}}^{2}$ & $-\Delta P \pi r_{o_{2}}^{2}-\rho g D \pi \Delta r_{2}^{2}$ & 0 \\
\hline Top of DC & $\Delta \rho g D_{2} \pi \Delta r_{2}^{2}-\rho g D_{1} \pi \Delta r_{2}^{2}-\Delta P \pi r_{o_{2}}^{2}$ & $-\Delta P \pi r_{o_{2}}^{2}-\rho g D_{1} \pi \Delta r_{2}^{2}$ & $\Delta \rho \Delta r_{2}^{2} g \pi D_{2}$ \\
\hline Btm of DP & $\Delta \rho g D_{2} \pi \Delta r_{2}^{2}-\rho g D_{1} \pi \Delta r_{1}^{2}-\Delta P \pi r_{o_{1}}^{2}$ & $-\Delta P \pi r_{o_{2}}^{2}-\rho g D_{1} \pi \Delta r_{2}^{2}$ & $\Delta \rho \Delta r_{2}^{2} g \pi D_{2}$ \\
\hline Top of DP & $\Delta \rho g \pi\left[D_{1} \Delta r_{1}^{2}+D_{2} \Delta r_{2}^{2}\right]-\Delta P \pi r_{o_{1}}^{2}$ & $-\Delta P \pi r_{o_{1}}^{2}$ & $\Delta \rho g \pi\left[D_{1} \Delta r_{1}^{2}+D_{2} \Delta r_{2}^{2}\right]$ \\
\hline Over WH & $\Delta \rho g \pi\left[D_{1} \Delta r_{1}^{2}+D_{2} \Delta r_{2}^{2}\right]-\Delta P \pi r_{o_{1}}^{2}$ & 0 & $\Delta \rho g \pi\left[D_{1} \Delta r_{1}^{2}+D_{2} \Delta r_{2}^{2}\right]-\Delta P \pi r_{o_{1}}^{2}$ \\
\hline Hook load & \multicolumn{3}{|c|}{$\Delta \rho g \pi\left[D_{1} \Delta r_{1}^{2}+D_{2} \Delta r_{2}^{2}\right]-\Delta P \pi r_{o_{1}}^{2}=$ Static weight $-\Delta P \pi r_{o_{1}}^{2}$} \\
\hline
\end{tabular}

where $\Delta \rho=\left(\rho_{\text {pipe }}-\rho_{\text {fluid }}\right)$ and $\Delta r_{k}^{2}=\left(r_{o_{k}}^{2}-r_{i_{k}}^{2}\right)$, where $k=1 \rightarrow$ drill pipe, and $k=2 \rightarrow$ drill collar.

Table C-4 - Forces in drill string with external loading in both drill pipe and annulus

\begin{tabular}{|l|c|c|c|}
\hline & Piston force & Avg. hydrostatic force & Deviatoric force \\
\hline Btm of DC & $-(\rho g D+\Delta P) \pi \Delta r_{2}^{2}$ & $-(\rho g D+\Delta P) \pi \Delta r_{2}^{2}$ & 0 \\
\hline Top of DC & $\pi \Delta r_{2}^{2}\left[\Delta \rho g D_{2}-\left(\rho g D_{1}+\Delta P\right)\right]$ & $-\left(\rho g D_{1}+\Delta P\right) \pi \Delta r_{2}^{2}$ & $\Delta \rho \Delta r_{2}^{2} g \pi D_{2}$ \\
\hline Btm of DP & $\pi \Delta r_{2}^{2} \Delta \rho g D_{2}-\left(\rho g D_{1}+\Delta P\right) \Delta r_{1}^{2}$ & $-\left(\rho g D_{1}+\Delta P\right) \pi \Delta r_{1}^{2}$ & $\Delta \rho \Delta r_{2}^{2} g \pi D_{2}$ \\
\hline Top of DP & $\Delta \rho g \pi\left[D_{1} \Delta r_{1}^{2}+D_{2} \Delta r_{2}^{2}\right]-\Delta P \pi \Delta r_{1}^{2}$ & $-\Delta P \pi \Delta r_{1}^{2}$ & $\Delta \rho g \pi\left[D_{1} \Delta r_{1}^{2}+D_{2} \Delta r_{2}^{2}\right]$ \\
\hline Over WH & $\Delta \rho g \pi\left[D_{1} \Delta r_{1}^{2}+D_{2} \Delta r_{2}^{2}\right]-\Delta P \pi \Delta r_{1}^{2}$ & $\Delta P \pi r_{i_{1}}^{2}$ & $\Delta \rho g \pi\left[D_{1} \Delta r_{1}^{2}+D_{2} \Delta r_{2}^{2}\right]-\Delta P \pi r_{o_{1}}^{2}$ \\
\hline Hook load & \multicolumn{3}{|c|}{$\Delta \rho g \pi\left[D_{1} \Delta r_{1}^{2}+D_{2} \Delta r_{2}^{2}\right]-\Delta P \pi r_{o_{1}}^{2}=$ Static weight $-\Delta P \pi r_{o_{1}}^{2}$} \\
\hline
\end{tabular}

where $\Delta \rho=\left(\rho_{\text {pipe }}-\rho_{\text {fluid }}\right)$ and $\Delta r_{k}^{2}=\left(r_{o_{k}}^{2}-r_{i_{k}}^{2}\right)$, where $k=1 \rightarrow$ drill pipe, and $k=2 \rightarrow$ drill collar. 
Table D-1 - Overall buoyancy factors for tapered string.

\begin{tabular}{lcc}
\hline Pipe: & Depth $m$ TVD & Buoyancy factor, $\beta$ \\
\hline Drill pipe -1 & $0-1000$ & $\beta_{4}$ \\
Drill pipe -2 & $1000-1500$ & $\beta_{3}$ \\
HWDP & $1500-1800$ & $\beta_{2}$ \\
Drill collars & $1800-1900$ & $\beta_{1}$ \\
\hline
\end{tabular}

Table D-2 - Cumulative buoyancy factors

\begin{tabular}{|c|c|c|c|}
\hline Drill string & $\beta$ & Numeric expression, $\beta$ & Numeric value, $\beta$ \\
\hline Drill collars & $\beta_{1}$ & $1-\frac{1.4[\text { s.g. }] 8^{2}\left[i n^{2}\right]-1.8[\text { s.g. }] 3^{2}\left[i n^{2}\right]}{7.8[\text { s.g. }]\left(8^{2}\left[\operatorname{in}^{2}\right]-3^{2}\left[i n^{2}\right]\right)}$ & 0.83 \\
\hline HWDP & $\beta_{2}$ & $1-\frac{100[\mathrm{~m}]\left(1.4 \cdot 8^{2}-1.8 \cdot 3^{2}\right)+300[\mathrm{~m}]\left(1.4 \cdot 5^{2}-1.8 \cdot 3^{2}\right)}{7.8\left\{100[\mathrm{~m}]\left(8^{2}-3^{2}\right)+300[\mathrm{~m}]\left(5^{2}-3^{2}\right)\right\}}$ & 0.84 \\
\hline Drill pipe -2 & $\beta_{3}$ & $1-\frac{\left\{\begin{array}{c}100\left(1.4 \cdot 8^{2}-1.8 \cdot 3^{2}\right)+300\left(1.4 \cdot 5^{2}-1.8 \cdot 3^{2}\right) \\
+500\left(1.4 \cdot 5^{2}-1.8 \cdot 4^{2}\right)\end{array}\right\}}{7.8\left\{100\left(8^{2}-3^{2}\right)+300\left(5^{2}-3^{2}\right)+500\left(5^{2}-4^{2}\right)\right\}}$ & 0.86 \\
\hline Drill pipe -1 & $\beta_{4}$ & $1-\frac{\left\{\begin{array}{c}100\left(1.4 \cdot 8^{2}-1.8 \cdot 3^{2}\right)+300\left(1.4 \cdot 5^{2}-1.8 \cdot 3^{2}\right) \\
+500\left(1.4 \cdot 5^{2}-1.8 \cdot 4^{2}\right)+1000\left(1.4 \cdot(65 / 8)^{2}-1.8 \cdot 5^{2}\right)\end{array}\right\}}{7.8\left\{\begin{array}{c}100\left(8^{2}-3^{2}\right)+300\left(5^{2}-3^{2}\right) \\
\left.+500\left(5^{2}-4^{2}\right)+1000\left((65 / 8)^{2}-5^{2}\right)\right\}\end{array}\right.}$ & 0.88 \\
\hline
\end{tabular}

\section{Appendix figures}
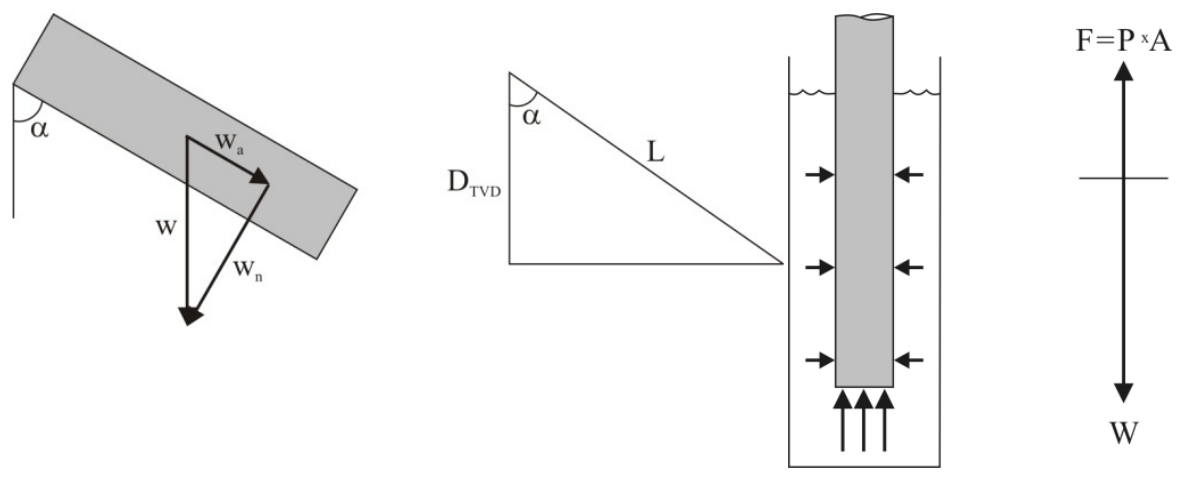

Figure A-1: Weight of pipe in inclined borehole

Figure B-1: Weight of a vertical submerged pipe.

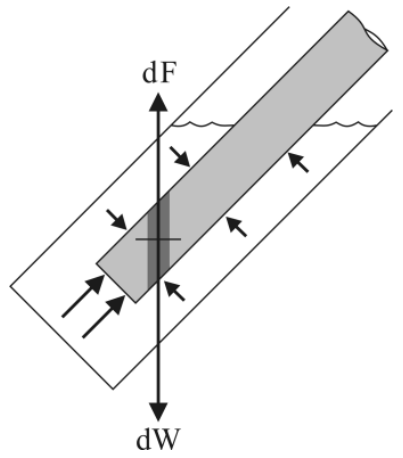

Figure B-2: Weight of submerged deviated pipe.

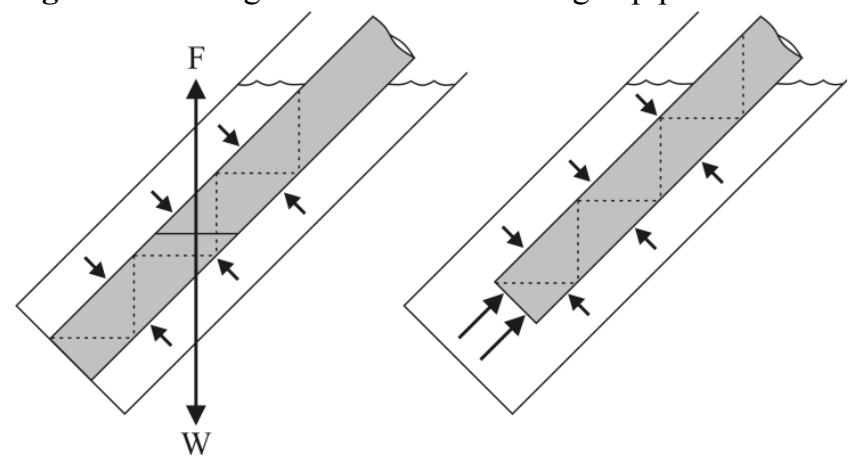

Figure B-3: Small effect of end condition (byouancy force is accumulated along pipe). 

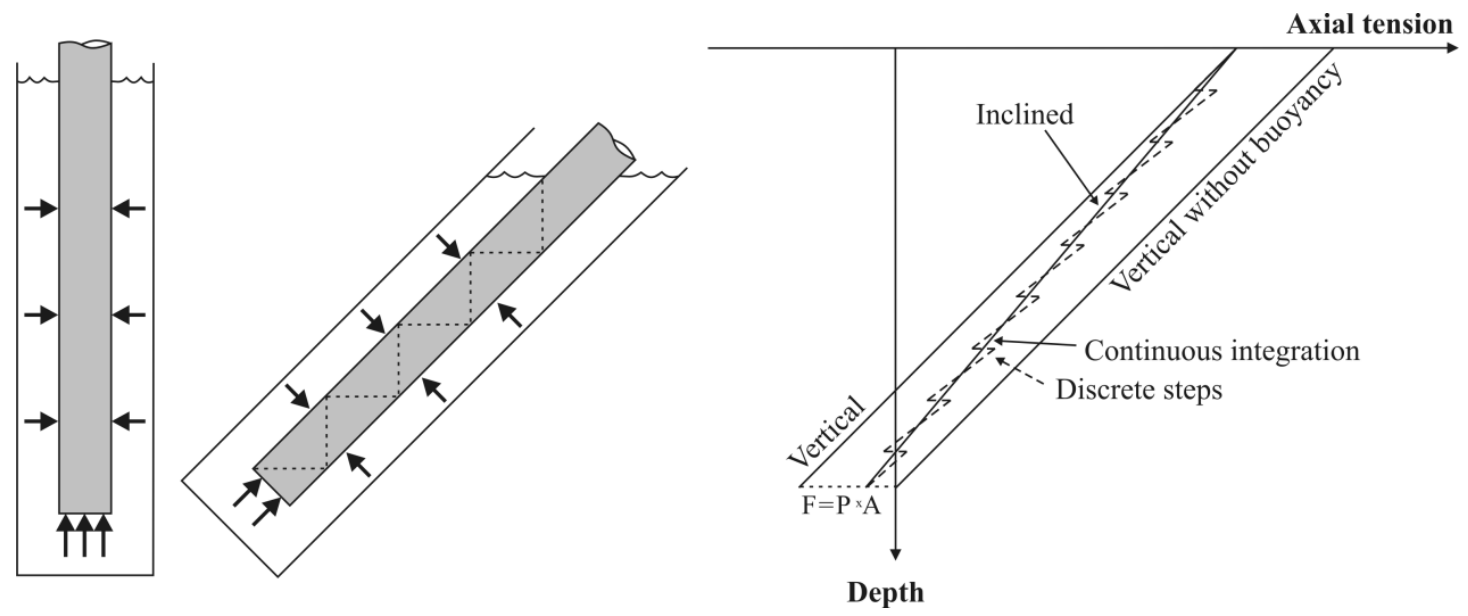

Figure B-4: Difference in position where the buoyant force applies.

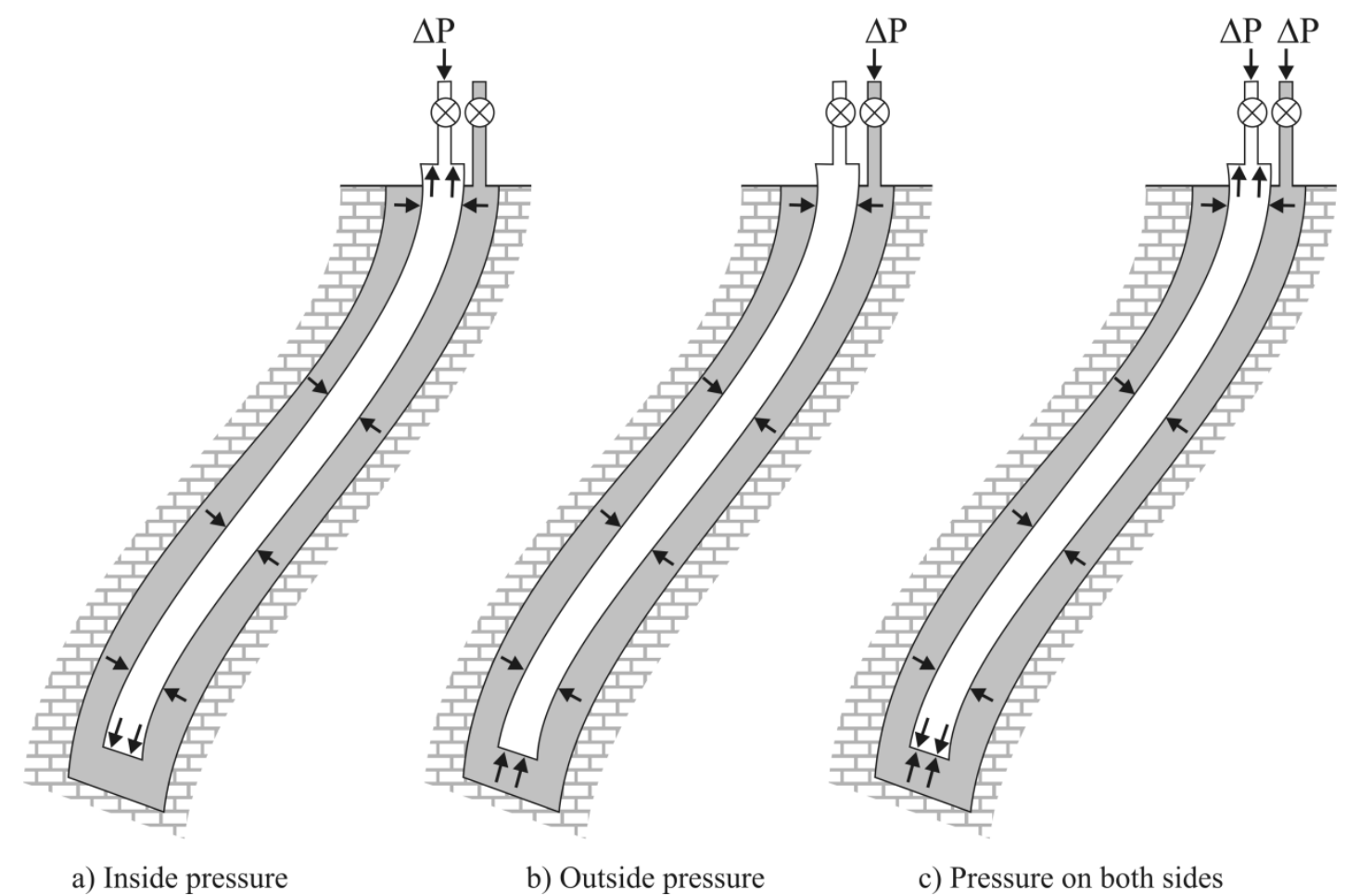

Figure C-1: Surface applied pressures 


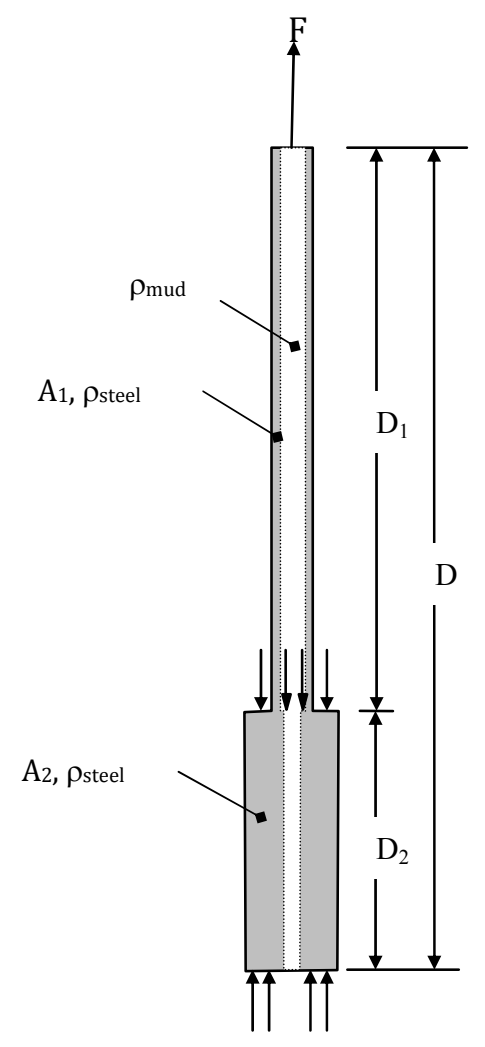

a) Drill string schematics

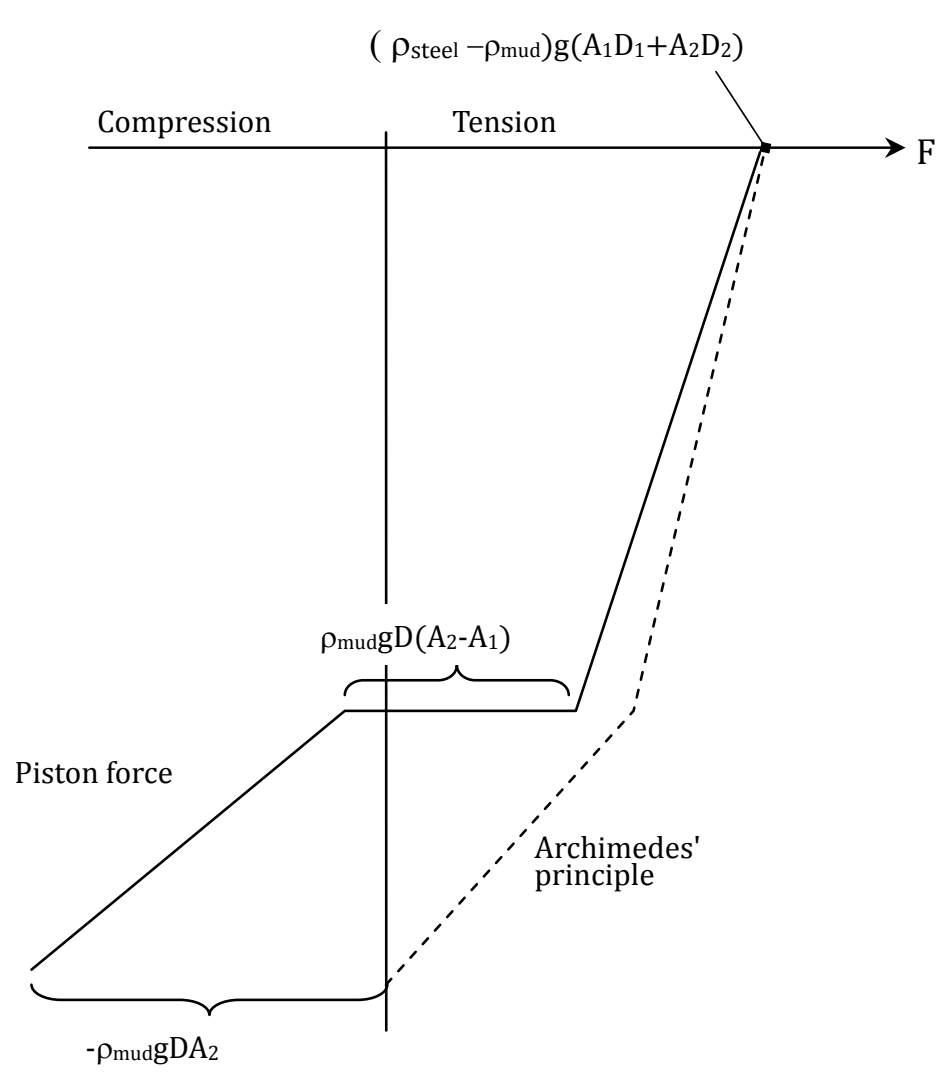

b) Forces in drill string

Figure C-2: Forces in the drill string based on the piston force principle. 